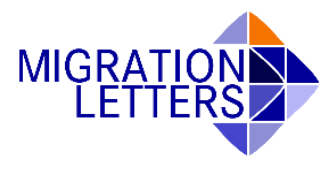

First Submitted: 25 May 2020 Accepted: 16 September 2020

DOI: https://doi.org/10.33182/ml.v17i5.1013

\title{
Reflections on Collective Insecurity and Virtual Resistance in the times of COVID-19 in Malaysia
}

\author{
Linda A. Lumayag ${ }^{1}$, Teresita C. del Rosario ${ }^{2}$ and Frances S. Sutton ${ }^{3}$
}

\begin{abstract}
Environments of human insecurity are a widespread problem in our globalised world, particularly for migrant workers, one of the most vulnerable groups in society today. These experiences of insecurity have been heightened in the context of the COVID-19 pandemic. In this article, we examine the collective experience of insecurity among migrant workers in Malaysia. In our analysis, we outline collective insecurity at two levels: the micro level of migrant workers' daily, subjective experiences of insecurity; and the macro level, in which insecurity is a consequence of structural forces, specifically the globalisation of labour. These two levels interact symbiotically, producing states of insecurity that are concretely experienced as anxiety and fear. Migrant workers in Malaysia also practice agency through small forms of resistance that they use to bolster one another and reduce their insecure experiences. Throughout the COVID-19 pandemic and subsequent Movement Control Order (MCO) in Malaysia, migrant workers have been further marginalised by the state, but they have also become connected to one another through acts of solidarity and resistance. However, the sustainability of these forms remains unclear.
\end{abstract}

Keywords: collective insecurity; virtual resistance; Malaysia; COVID-19; migrant workers; migration

\section{Introduction}

No one escapes insecurity today. Environments of insecurity created by conflict have become a basic human experience in our increasingly globalised world. Those who experience more conflict at the micro (individual), mezzo (household, community), and macro (state, nation) levels are subject to higher amounts of perceived insecurity (Sirkeci, 2009). This article is an attempt to interrogate the environment of human insecurity experienced by migrant workers in Malaysia, where the COVID-19 pandemic has forced the tension across the micro, mezzo, and macro levels of conflict to come to the fore. We argue that migrants experience collective insecurity, which has intensified in the context of the COVID-19 pandemic (Cohen, 2020). Further, we argue that Malaysian migrants have developed forms of resistance in response to their collective insecurity, which have also become more pronounced in the context of Coronavirus.

Previous studies on human insecurity have incorporated frameworks from early security studies, focusing on broad concepts such as nation-states, sovereignty, territoriality, and nationalism, following the principle of Westphalian sovereignty (Vietti \& Scribner, 2013). In security studies, migration is often examined at the macro level of institutions, organisations, and

\footnotetext{
${ }^{1}$ Linda A. Lumayag, Program Coordinator and Senior Lecturer, Politics and Government, Faculty of Social Sciences \& Humanities, Universiti Malaysia Sarawak, 94300 Kota Samarahan, Sarawak, Malaysia. E-mail: allinda@unimas.my.

${ }^{2}$ Teresita C. Del Rosario, Senior Research Associate, Asia Research Institute, National University of Singapore, 10 Kent Ridge Crescent, AS-8, Level 07-27, Singapore. E-mail: delrosatess@gmail.com.

${ }^{3}$ Frances S. Sutton, PhD Candidate, Department of Anthropology, College of Arts and Sciences, Ohio State University, 4034 Smith Laboratory, 174 W. 18th Avenue, Columbus, Ohio, United States. E-mail: sutton.373.osu.edu.
} 